results in order to ensure maximum effectiveness of the methods used.

Controlled pulmonary ventilation is technically simple and safe, but requires a high degree of attention and should not be undertaken without adequate facilities and experience. Clearly there is much to be learned about the support of vital organs during intercurrent illness and the use of instruments for temporarily taking over their function. Nevertheless, this unit has undoubtedly been responsible for the saving of lives that in the absence of readily available specialized therapy would have been lost.
REFERENCES

Allen, T. H., and Steven, I. M. (1965). Brit. F. Anaesth., 37, 566.

Astrup, P., Jørgensen, K., Siggard Andersen, O., and Engel, K. (1960). Lancet, 1, 1035.

Bush, G. H. (1963). Brit. F. Anaesth., 35, 322.

Darby, T. D., Aldinger, E. E., Gadsden, R. H., and Thrower, W. B. (1960). Circulat. Res., 8, 1242.

Gerst, P. H., Fleming, W. H., and Malm, J. R. (1964). Surg. Forum, 15, 242.

Rees, G. J., and Owen-Thomas, J. B. (1966). Brit. F. Anaesth., 38, 901.

Stewart, J. S. S. (1964). Brit. med. F., 1, 476.

- Stewart, W. K., and Gillies. H. G. (1962). Lancet, 2, 964.

\title{
Subclinical Small-intestinal Disease in East Pakistan
}

\author{
JOHN LINDENBAUM,* M.D.; A. K. M. JAMIUL ALAM,* M.B.; THOMAS H. KENT, $\dagger$ M.D.
}

Brit. med. F., 1966, 2, 1616-1619

Investigators in Thailand, South India, Puerto Rico, Haiti, and West Pakistan have noted a remarkably high incidence of malabsorption and histological evidence of chronic enteritis in surveys of asymptomatic apparently normal members of the native-born population (Sprinz et al., 1962 ; Baker et al., 1962 ; Angel et al., 1963 ; Klipstein et al., 1966 ; Russell et al., 1966). These studies have usually been carried out as control observations in connexion with the investigation of patients with diarrhoeal illnesses. Reduced absorptive capacity for xylose has been shown, but the absorption of other substances has not been widely studied, and there has been little in the way of systematic inquiry into the problem. In this investigation it was decided (1) to determine the incidence of malabsorption in a group of asymptomatic East Pakistanis ; (2) to test the absorption of substances other than xylose to gain a fuller picture of the extent of derangement of small-bowel function; (3) to correlate the presence of malabsorption with factors such as economic status, body weight, parasitism, and anaemia ; and (4) to observe the natural history of subjects with evidence of subclinical bowel disease and the effects of treatment with tetracycline and folic acid on small-intestinal function.

\section{Methods and Materials}

Adult Pakistani employees of the Pakistan-SEATO Cholera Research Laboratory were asked to volunteer for the study. Of 113 employees approached 106 agreed to take part. They represent a cross-section of the total employee group, with a wide range in occupation (Table I) and economic status (Fig. 1). Absorption tests were performed at the laboratory under the supervision of a nurse trained in metabolic procedures. At the time of study all subjects were free of diarrhoea, though $6 \%$ of the group had experienced chronic diarrhoea during the year prior to the study.

The five-hour urinary excretion of D-xylose after a $25-\mathrm{g}$. dose by mouth was measured by the method of Roe and Rice (1948). Normal values for this laboratory in asymptomatic Europeans and Americans range from 5 to $10 \mathrm{~g}$. Folic-acid absorption was studied by microbiological assay of serum with Streptococcus faecalis after a dose of $40 \mu \mathrm{g}$. of folic acid per $\mathrm{kg}$. by mouth. Values of $>40 \mathrm{~m} \mu \mathrm{g} . / \mathrm{ml}$. at one or two hours are

- Pakistan-SEATO Cholera Research Laboratory, Dacca, East Pakistan, and First Medical Division (Columbia University), Bellevue Hospital, New York.

t Department of Experimental Pathology, Walter Reed Army Institute of Research, Washington, D.C., U.S.A.

Requests for reprints should be sent to Dr. John Lindenbaum, First Medical Division, Bellevue Hospital, 462 First Avenue, New York, New York 10016, U.S.A. regarded as normal (Chanarin et al., 1958). The 24-hour urinary excretion of vitamin $B_{12}$ was measured after an oral dose of $1 \mu \mathrm{g}$. of cobalt-58-labelled cyanocobalamin (Amersham)

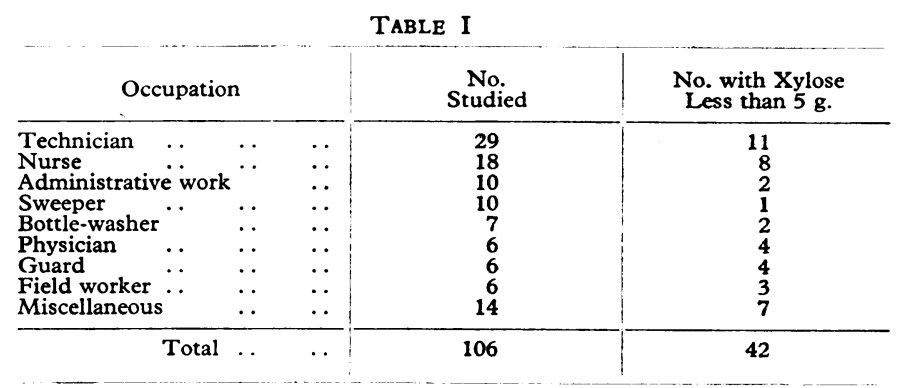

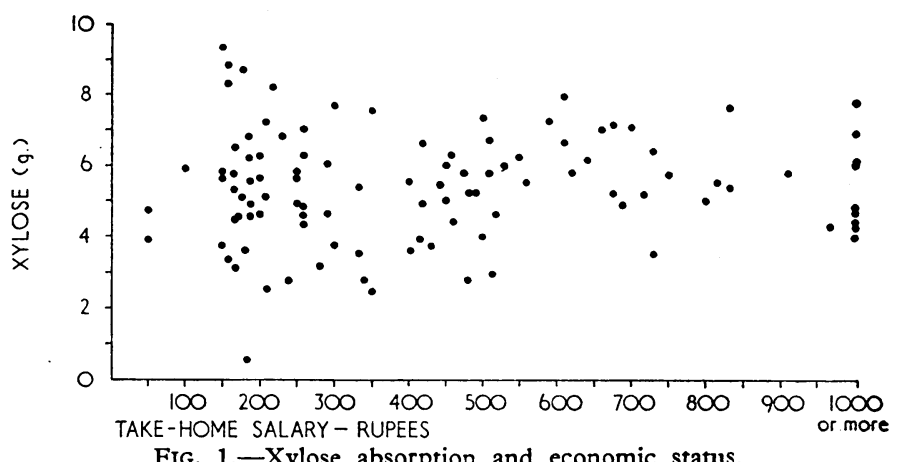

given with intrinsic factor and a parenteral "flushing" dose of $1 \mathrm{mg}$. non-radioactive vitamin $B_{12}$ (Schilling, 1953). Normal values in this laboratory are 8 to $26 \% / 24$ hours. Faecal fat was measured according to a modification (Jover and Gordon, 1962) of the method of van de Kamer et al. (1949) on 72-96-hour collections. An average daily excretion of $5 \mathrm{~g}$. or less was regarded as normal. Jejunal biopsies were obtained with the intestinal capsule of Crosby and Kugler (1957) and examined under the dissecting and light microscopes.

\section{Results}

\section{Xylose Absorption}

The mean xylose excretion of the 106 employees was $5.38 \mathrm{~g}$. (S.D. 1.81). The values follow a normal distribution curve. 
Forty-two $(39.6 \%)$ of the employees excreted less than 5 g., the lower limit of normal for the test.

\section{Vitamin $\mathbf{B}_{12}$ Absorption}

The Schilling test was performed on 30 employees, 14 of whom had low xylose values (Table II). Absorption of vitamin $B_{12}$ was subnormal in six $(20 \%)$, four of whom had xylose malabsorption.

TABLE II.-Absorption Studies and fejunal Biopsies in Pakistani

\begin{tabular}{|c|c|c|c|c|c|}
\hline \multicolumn{6}{|c|}{ Employees } \\
\hline Subject & $\begin{array}{c}\text { Xylose } \\
(\mathrm{g} .)\end{array}$ & $\underset{\text { Test }}{\text { Schilling }}$ & $\begin{array}{l}\text { Faecal Fat } \\
(\text { g./d.) }\end{array}$ & $\begin{array}{c}\text { Peak Folic } \\
\text { Acid } \\
\text { Level } \\
(\mathrm{m} \mu \mathrm{g} \cdot / \mathrm{ml})\end{array}$ & $\begin{array}{c}\text { Jejunal } \\
\text { Biopsy } \\
\text { Dissecting } \\
\text { Microscope }\end{array}$ \\
\hline \multicolumn{6}{|c|}{ Subjects with Abnormal Xylose } \\
\hline $\begin{array}{c}1 \\
2 \\
3 \\
4 \\
5 \\
6 \\
7 \\
8 \\
9 \\
10 \\
11 \\
12 \\
13 \\
14 \\
15\end{array}$ & $\begin{array}{l}3 \cdot 9 \\
2 \cdot 1 \\
4 \cdot 2 \\
4 \cdot 3 \\
4 \cdot 7 \\
3 \cdot 7 \\
3 \cdot 5 \\
1 \cdot 2 \\
3 \cdot 6 \\
4 \cdot 7 \\
4 \cdot 0 \\
2 \cdot 8 \\
3 \cdot 1 \\
2 \cdot 7 \\
4 \cdot 5\end{array}$ & $\begin{array}{r}20.0 \% \\
4.8 \% \\
13.9 \% \\
11.8 \% \\
5.2 \% \\
12.5 \% \\
9.1 \% \\
7.8 \% \\
13.2 \% \\
16.1 \% \\
3.8 \% \\
21.5 \% \\
3.0 \% \\
9.8 \%\end{array}$ & $\begin{array}{l}2.3 \\
1.7 \\
1.6 \\
1.1 \\
5.8\end{array}$ & $\begin{array}{r}>100 \\
>100 \\
>100 \\
100 \\
80 \\
94 \\
>100\end{array}$ & $\begin{array}{l}\mathrm{L} \gg \mathrm{R}, \mathrm{F} \\
\mathrm{L} \gg \mathrm{F}, \mathrm{C}\end{array}$ \\
\hline \multicolumn{6}{|c|}{ Subjects with Normal Xylose } \\
\hline $\begin{array}{l}16 \\
17 \\
18 \\
19 \\
20 \\
21 \\
22 \\
23 \\
24 \\
25 \\
26 \\
27 \\
28 \\
29 \\
30 \\
31 \\
32\end{array}$ & $\begin{array}{l}7.0 \\
5.6 \\
5.2 \\
6.2 \\
7.7 \\
6.5 \\
6.8 \\
5.2 \\
7.9 \\
6.8 \\
5.7 \\
7.5 \\
6.1 \\
5.5 \\
9.3 \\
6.5 \\
5.4\end{array}$ & $\begin{array}{r}20.0 \% \\
11.4 \% \\
14.9 \% \\
12.3 \% \\
11.9 \% \\
14.3 \% \\
4.3 \% \\
16.1 \% \\
8.6 \% \\
11.8 \% \\
15.9 \% \\
21.3 \% \\
12.0 \% \\
15.3 \% \\
3.7 \% \\
9.7 \%\end{array}$ & $\begin{array}{l}4.3 \\
1.7 \\
5.0 \\
1.4 \\
3.3 \\
2.4 \\
3.9 \\
1.8 \\
2.8\end{array}$ & $\begin{array}{r}>100 \\
80 \\
>100\end{array}$ & $\begin{array}{l}\mathrm{L}>\mathrm{F} \\
\mathrm{L}>\mathrm{F} \\
\mathrm{L}>\mathrm{F} \\
\mathrm{L} \\
\mathrm{L}>\mathrm{R}, \mathrm{C}, \mathrm{F} \\
\mathrm{L}>\mathrm{R}, \mathrm{C}\end{array}$ \\
\hline Normal & $5 \cdot 0-10 \cdot 0$ & $8-26 \%$ & $5 \mathrm{~g}$. or less & $>40$ & $\mathbf{F}>\mathbf{L}$ \\
\hline
\end{tabular}

\section{Faecal Fat}

Daily faecal fat excretion was normal in 14 subjects and borderline ( $5.8 \mathrm{~g}$.) in one (Table II). The borderline value was in an employee with low xylose and Schilling values. Of the 14 with normal faecal fat excretion, four had xylose malabsorption and another absorbed both xylose and vitamin $B_{12}$ poorly.

\section{Folic Acid Absorption}

In 11 individuals (of whom six had low xylose values and another had impaired absorption of both xylose and vitamin $B_{12}$ ) peak serum folic acid levels after the test dose by mouth were well within normal limits in every instance (Table II).

\section{Jejunal Biopsies}

Small-intestinal biopsies from the first or second loop of jejunum were obtained from 11 subjects, four of whom absorbed xylose poorly. With the exception of one who had mild chronic diarrhoea, all these subjects denied gastrointestinal symptoms. Under the dissecting microscope, leaf-like villi predominated in all the mucosal specimens (Table II). Finger villi, the predominant villous form seen in biopsies from normal individuals in England and North America, were observed in all specimens except two, but always in smaller numbers than the leaf forms. Ridged and/or convoluted villi were present as well in all the four subjects with malabsorption of xylose, but in only two of the seven with normal absorption. None of the histological sections of the 11 biopsies was normal when compared with North American control subjects. All of the Pakistani biopsies showed mild to moderate infiltration of the lamina propria with plasma cells, lymphocytes, and eosinophils, with increase in crypt length, and variable diminution in villus height (Fig. 2). None of the specimens appeared flat, with absent villi, such as is seen in coeliac sprue in relapse. Several biopsies resembled those obtained from patients with tropical sprue of mild to moderate clinical severity. In this small group of subjects there was no difference in histological appearance between those with normal and those with low xylose absorption.

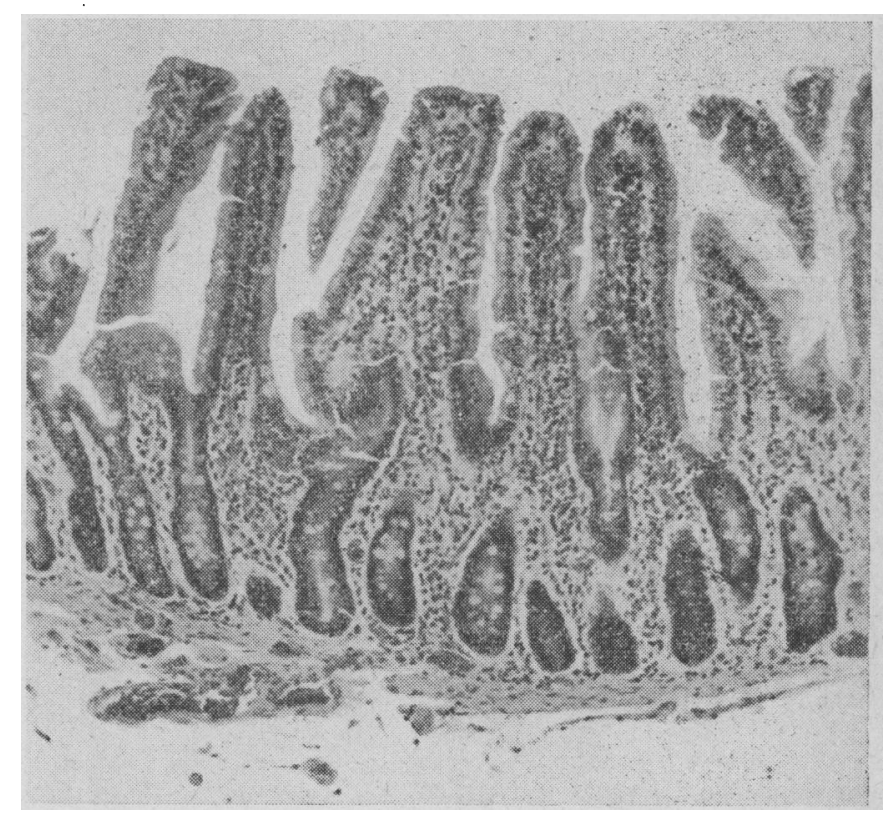

Fig. 2.- Jejunal mucosa from subject 28, representative of the mild jejunitis present in the subjects studied. Crypts are elongated and there is slight diminution of villous height. Chronic inflammatory cells are moderately increased in the lamina propria. Villous epithelium appears well preserved. $(\times 100$. $)$

The sections were compared with those obtained from young asymptomatic males from West Pakistan in a recent study (Russell et al., 1966). The character and degree of mucosal damage was similar in subjects from the two wings of Pakistan.

\section{Correlation of Malabsorption with Other Factors}

No correlation was apparent between inability to absorb xylose normally and occupation (Table I), salary (Fig. 1; $r=0.06$ ), age, body weight, blood haemoglobin level, eosinophil counts, number of daily bowel movements, presence of constipation, or brief gastroenteritis-like episodes of diarrhoea

TABLE III.-Comparison of Laboratory and Clinical Data on 100 Subjects*

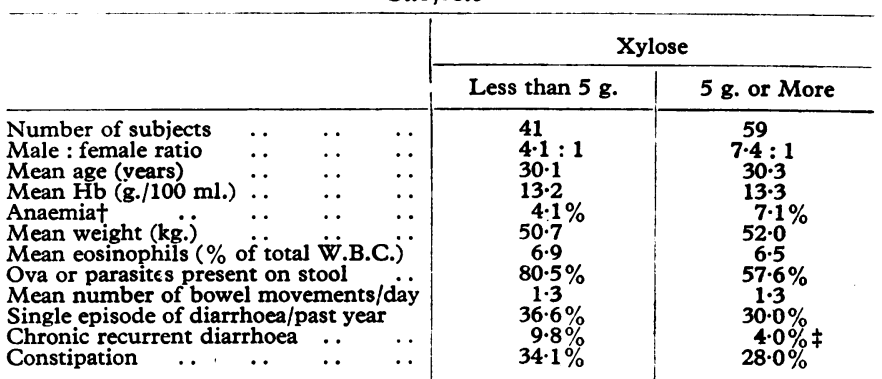

* Complete data on each of the points listed werz available on 100 of the 106

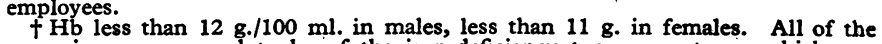
$+\mathrm{Hb}$ less than $12 \mathrm{~g} .100 \mathrm{ml}$. in males, less than $11 \mathrm{~g}$. in females. All of the
anaemias were proved to be of the iron-deficiency type, except one which was

₹ Difference not statistically significant; $P>0.2$. 
during the year preceding the time of study (Table III). There were a few subjects with mild chronic diarrhoea among the employees who absorbed xylose normally and among those who did not (Table III).

The presence of parasites on stool examination was a significantly more common finding in the subjects with impaired xylose absorption than in those with normal absorption (Table III) $\quad \mathrm{P}<0.05)$. For the two most common infestations the difference was statistically significant for ascaris $(P<0.01)$ but not for hookworm $(0.1>\mathrm{P}>0.05)$.

\section{Variability of Xylose Absorptive Capacity in Individual Subjects}

In 23 subjects with initially low xylose absorption the test was repeated from one to five times at intervals during a period of 18 months. In 14 of the 23 subjects malabsorption of xylose was shown at each repetition of the test ; in four xylose absorption was impaired on all but one of four or five occasions; and in the remaining five xylose absorption became normal 5 to 12 months after the initial test and remained normal on subsequent testing. The data can be summarized in another way: in 53 repeat xylose tests on 23 individuals with initially low values, $39(74 \%)$ were again low. None of the changes could be related to changes in body weight or symptomatology.

In 12 subjects with initially normal xylose values the test was repeated 9 to 18 months later. In nine xylose was again absorbed normally; three had developed malabsorption, though they were asymptomatic.

\section{Effects of Therapy with Tetracycline or Folic Acid}

Six asymptomatic subjects with consistently impaired xylose absorption over a baseline period of 12 to 14 months were given a three-weeks course of tetracycline by mouth $(1 \mathrm{~g}$./day). Repeat xylose tests immediately after the course of treatment showed no improvement in five and an increase from 4.1 to $5.7 \mathrm{~g}$. in the sixth. In four of the six subjects appetite increased while on the antibiotic, and weight gains of 1.1 to $1.8 \mathrm{~kg}$. were noted in three; weight remained stable in the other three.

Four of those who showed no improvement in absorption after the three-weeks course of tetracycline were subsequently given folic acid $15 \mathrm{mg}$. daily by mouth for 21 days. In addition, three other subjects with consistently impaired xylose absorption who had not received tetracycline were given the three-weeks course of folic acid. In six of the seven there was no improvement in absorption over baseline values after folic acid therapy ; in one xylose excretion rose from 4.7 to $6.4 \mathrm{~g}$. One subject, whose absorption did not improve, gained $1.7 \mathrm{~kg}$. during the course of treatment with the vitamin. None of the subjects reported any symptomatic benefit.

\section{Discussion}

Jejunal biopsies obtained from " control" subjects free from gastrointestinal symptoms have shown abnormalities of smallintestinal morphology in the majority of native-born inhabitants of tropical countries. In South India, for example, jejunal villous architecture was abnormal under the dissecting microscope in all of 25 control subjects studied by Baker et al. (1962), and abnormalities were present in histological sections in most. These investigators felt that jejunal biopsy could not differentiate patients with severe tropical sprue from apparently normal individuals. Similar abnormalities were found in the majority of a group of Ugandan subjects who had no known gastrointestinal disease (Banwell et al., 1964), and in nine of ten biopsies from Chinese and Indian subjects in Singapore (England and O'Brien, 1966). Histological changes consistent with a chronic enteritis were present in almost all of 27 asymptomatic Thai individuals (Sprinz et al., 1962), in all of 47 asymptomatic West Pakistanis (Russell et al., 1966), and in all of seven asymptomatic Haitians (Klipstein et al., 1966). In the present study all of the biopsy specimens obtained from symptom-free East Pakistanis were abnormal by both dissecting and light microscopy, and the changes were similar to those noted by investigators in other tropical countries.

Xylose absorption was subnormal in 20 to $100 \%$ of asymptomatic subjects studied in South India (Baker et al., 1962), Thailand (Sprinz et al., 1962), West Pakistan (Russell et al., 1966), Puerto Rico (Angel et al., 1963), and Haiti (Klipstein et al., 1966). Little information concerning the absorption of substances other than xylose has been provided in these reports, though Baker et al. (1962) found faecal fat excretion to be normal in 17 out of 18 control subjects in South India. In Haiti, Klipstein et al. (1966) showed subnormal vitamin-B $\mathrm{B}_{12}$ absorption in each of two asymptomatic subjects and normal folic acid absorption in all of three individuals. In the present investigation $40 \%$ of 106 East Pakistani subjects absorbed xylose poorly. Vitamin- $\mathrm{B}_{12}$ absorption was less frequently impaired, and absorption of folic acid and fat absorption was usually normal. The finding of normal fat and folic acid absorption in control subjects with other evidence of smallintestinal disease is consistent with the studies reported from India and Haiti.

The high incidence of xylose malabsorption suggests that the lesion predominantly involves the upper small intestine (Fordtran et al., 1962), though one-fifth of the subjects did not absorb vitamin $B_{12}$ normally, indicating dysfunction of the ileum (Booth and Mollin, 1959). It is of interest that folic acid was absorbed normally in individuals with poor absorption of xylose, since both substances are believed to be absorbed predominantly in the upper small bowel (Herbert, 1959 ; Fordtran et al., 1962 ; Booth et al., 1964); and in patients with malabsorption syndromes other than tropical sprue impairment of xylose absorption is usually accompanied by malabsorption of folic acid (Chanarin and Bennett, 1962). In patients with tropical sprue, however, xylose absorption may be reduced while folic acid absorption remains normal (Lindenbaum, 1965a ; Paterson et al., 1965 ; Klipstein et al., 1966). Discrepancies in the absorption of one substance or another, such as those encountered in the present study, are not unusual in patients with small-intestinal disease and cannot be well explained at this time.

It is apparent, then, that both morphological and functional evidence of subclinical small-intestinal disease is readily demonstrable in most if not all residents of tropical countries. The cause of this subclinical bowel disease is at present obscure. It appears to occur at all economic and social levels of the Pakistani population, as malabsorption is as common in physicians as in bottle-washers or guards (Table I). While longstanding protein malnutrition has been suggested as a possible cause of these abnormalities (Stanfield et al., 1965), their presence in this study in Pakistanis at all economic levels (including some individuals from upper-class families) would seem to make even subclinical malnutrition an unlikely cause, as does the lack of correlation between malabsorption and body weight. In addition, well-nourished American Peace Corps volunteers develop similar abnormalities in absorptive function and small-bowel morphology after a few months' residence in Pakistan (Lindenbaum et al., 1966).

Present evidence suggests that the intestinal lesions found in native-born inhabitants of tropical countries are acquired rather than genetic. They are too widespread in different tropical areas of the world (including Asia, Africa, and South America) to be attributable to a genetic variant ; they are absent in South Indian and Ugandan stillborn foetuses (Baker et al., 1962; Stanfield et al., 1965) ; and, as mentioned, they develop in American Peace Corps volunteers soon after exposure to the tropical environment. 
The significance of the higher incidence of parasitism in our Pakistani employees with malabsorption is uncertain. It is doubtful whether infestation with hookworms or roundworms, the most common parasites found in these subjects, is directly responsible for malabsorption (Layrisse et al., 1964). Possibly the presence of bowel dysfunction predisposes to the establishment of a parasitic infection. On the other hand, the high incidence of parasites may indicate exposure to a more heavily contaminated environment, suggesting the possible role of bacterial infection or microbial toxins in producing bowel damage. Staphylococcal enterotoxin, for example, has been shown to cause reversible histological damage to the small bowel of monkeys (Kent, 1966). Acute intestinal infections may cause transient malabsorption and bowel damage in humans (King and Joske, 1960 ; Lindenbaum, 1965b). It is possible that subclinical exposure to an infectious agent or a microbial toxin may be responsible for the bowel damage nearly universal in residents of tropical countries. The possible contribution of irritating foods, such as spices or betel nut, has been suggested by Sprinz et al. (1962), and will bear further investigation, though the apparently global distribution of the intestinal lesions argues against a single dietary toxin common to all tropical areas.

Klipstein et al. (1966) have suggested that, in view of the resemblance of the intestinal lesions to those seen in patients with tropical sprue, all or almost all residents of tropical countries have tropical sprue in a subclinical form, while only a few develop the overt clinical manifestations of the disease. While this hypothesis is attractive, it must be remembered that the mucosal changes found in tropical sprue as well as in asymptomatic subjects are nonspecific, and appear to represent the characteristic response of the small-bowel mucosa to a large variety of noxious influences (Sprinz, 1962 ; Townley et al., 1964 ; Creamer, 1964 ; Collins, 1965). In addition, our subjects did not resemble patients with overt tropical sprue in that absorption did not improve after tetracycline therapy in five of the six individuals treated.

Considerable variability in xylose absorption was noted in our subjects when the test was repeated at intervals of several months. Absorption of the pentose changed from subnormal to normal or vice versa in about a quarter of the individuals under study, without apparent associated changes in well-being, weight, or other symptomatology. Careful attention was paid to rule out inadequacy of urine collection as a possible cause of these variations. The tendency for such spontaneous fluctuation requires repeated baseline studies over a prolonged period as well as cautious interpretation of results in evaluation of any attempts to improve absorptive function in these subjects by therapeutic measures. In subjects carefully selected with these considerations in mind, we were unable to find any improvement in xylose absorption after three-weeks courses of therapy with tetracycline or folic acid. Further studies, to determine the effect of manipulations of diet, more prolonged treatment with antibiotics, and changes from tropical to temperate environments, are in progress.

\section{Summary}

The majority of inhabitants of tropical countries appear to have subclinical small-intestinal disease. In a group of 106 East Pakistani subjects who were symptom-free or had minor gastrointestinal complaints xylose absorption was low in $40 \%$. Malabsorption of vitamin $\mathrm{B}_{12}$ was less common, and fat and folic acid were usually absorbed normally. The presence of malabsorption was not related to economic status. Jejunal biopsy specimens obtained from 11 subjects were abnormal under the dissecting microscope and in histological section. In individuals studied serially, xylose absorption was stable in most, though a minority showed unexplained variations in absorptive capacity. Three-weeks courses of tetracycline or folic acid did not improve xylose absorption.

This work was supported in part by Research Agreement No. 196802 between the National Institutes of Health, Bethesda, Maryland, U.S.A., and the Pakistan-SEATO Cholera Research Laboratory, and by grant AM-07183 AMP from the National Institutes of Health.

We wish to thank Dr. A. S. Benenson, Director of the PakistanSEATO Cholera Research Laboratory, and Colonel Helmuth Sprinz, chief of the Department of Experimental Pathology, Walter Reed Army Institute of Research, for encouragement and suggestions ; Mrs. Madhabi Ghose for careful nursing support ; and Mr. Mujibur Rahman and Mr. Bazlur Rahman for technical assistance.

\section{REFERENCES}

Angel, C. R., Guerra, R., Martinez, J., and Plough, I. C. (1963). Fed. Proc., 22, 550.

Baker, S. J., Ignatius, M., Mathan, V. I., Vaish, S. K., and Chacko, C. C. (1962). In Intestinal Biopsy, edited by G. E. W. Wolstenholme and M. P. Cameron, p. 84. London.

Banwell, J. G., Hutt, M. S. R., and Tunnicliffe, R. (1964). E. Afr. med. f., 41, 46.

Booth, C. C., MacIntyre, I., and Mollin, D. L. (1964). Quart. F. Med., 33, 401 .

- and Mollin, D. L. (1959). Lancet, 1, 18

Chanarin, I., Anderson, B. B., and Mollin, D. L. (1958). Brit. F. Haemat., 4, 156.

_ and Bennett, M. C. (1962). Brit. med. f., 1, 985.

Collins, J. R. (1965). Amer. F. clin. Path., 44, 36.

Creamer, B. (1964). Brit. med. F., 2, 1373.

Crosby, W. H., and Kugler, H. W. (1957). Amer. F. dig. Dis., 2, 236.

England, N. W. J., and O'Brien, W. (1966). Gut, 7, 128.

Fordtran, J. S., Soergal, K. H., and Ingelfinger, F. J. (1962). New Engl. 尹. Med., 267, 274.

Herbert, V. (1959). The Megaloblastic Anaemias, p. 53. New York and London.

Jover, A., and Gordon, R. S. (1962). 7. Lab. clin. Med., 59, 878.

Kent, T. H. (1966). Amer. F. Path., 48, 387.

King, M. J., and Joske, R. A. (1960). Brit. med. 7., 1, 1324.

Klipstein, F. A., Samloff, I. M., and Schenk, E. A. (1966). Ann. intern. Med., 64, 575.

Layrisse, M., Blumenfeld, N., Carbonell, L., Desenne, J., and Roche, M. (1964). Amer. F. trop. Med. Hyg., 13, 297.

Lindenbaum, J. (1965a). Unpublished observations.

- (1965b). Brit. med. 7., 2, 326.

- Kent, T. H., and Sprinz, H. (1966). Ann. intern. Med. In press.

Paterson, D. E., David, R., and Baker, S. J. (1965). Brit. F. Radiol., 38, 181 .

Roe, J. H., and Rice, E. W. (1948). F. biol. Chem., 173, 507.

Russell, P. K., Aziz, M. A., Ahmad, N., Kent, T. H., and Gangarosa, E. J. (1966). Amer. F. dig. Dis., 11, 296.

Schilling, R. F. (1953). f. Lab. clin. Med., 42, 860.

Sprinz, H. (1962). Fed. Proc., 21, 57.

- Sribhibhadh, R., Gangarosa, E. J., Benyajati, C., Kundel, D., and Halstead, S. (1962). Amer. f. clin. Path., 38, 43.

Stanfield, J. P., Hutt, M. S. R., and Tunnicliffe, R. (1965). Lancet, 2, 519.

Townley, R. R. W., Cass, M. H., and Anderson, C. M. (1964). Gut, 5, 51.

van de Kamer, J. H., ten Bokkel Huinink, H., and Weyers, H. A. (1949). f. biol. Chem., $177,347$. 